\title{
Novas espécies e novas ocorrências de Xenofrea (Coleoptera, Cerambycidae, Lamiinae)
}

\author{
Maria Helena M. Galileo ${ }^{1,3}$ \& Ubirajara R. Martins s, $^{2}$
}

1. Museu de Ciências Naturais, Fundação Zoobotânica do Rio Grande do Sul, Caixa Postal 1188, 90001-970 Porto Alegre, RS, Brasil.
2. Museu de Zoologia, Universidade de São Paulo, Caixa Postal 42494, 04218-970 São Paulo, SP, Brasil.
3. Bolsista do CNPq.

ABSTRACT. New species and new records on Xenofrea (Coleoptera, Cerambycidae, Lamiinae). Xenofrea apicalis Melzer, 1931 is recorded to Paraguay and X. triangularis Martins \& Galileo, 2005 to Brazil (Rondônia). New species described: X. fasciolata sp. nov. and $X$. camixaima sp. nov. from Brazil (Rondônia) and Bolivia (Santa Cruz); X. clarkei sp. nov., X. punctata sp. nov., X. nana sp. nov. from Bolivia (Santa Cruz); X. obscura sp. nov. from Argentina (Entre Ríos) and Bolivia (Santa Cruz).

KEYWORDS. Neotropical, new species, taxonomy, Xenofrea, Xenofreini.

RESUMO. Novos registros: Xenofrea apicalis Melzer, 1931 para o Paraguai e X. triangularis Martins \& Galileo, 2005 para o Brasil (Rondônia). Novas espécies: X. fasciolata sp. nov. e X. camixaima sp. nov. (Brasil: Rondônia e Bolívia: Santa Cruz); X. clarkei sp. nov., $X$. punctata sp. nov., X. nana sp. nov. (Bolívia: Santa Cruz); X. obscura sp. nov. (Argentina: Entre Ríos e Bolívia: Santa Cruz).

PALAVRAS-CHAVE. Neotropical, novas espécies, taxonomia, Xenofrea, Xenofreini.

O gênero Xenofrea Bates, 1885 foi estabelecido para quatro espécies e, até o momento, contava com 28 espécies: BATEs (1885) descreveu X. anomala, X. areolata, X. trigonalis e X. zonata; em 1931, MeLZER acrescentou X. apicalis; ZAJCIW (1961) publicou a descrição de $X$. lineatipennis; foram acrescentadas por Galileo \& Martins (1999), X. exotica e, em (2001), X. albofasciata e X. fulgida; Martins \& Galileo (2005) descreveram $X$. triangularis. NÉOUZE \& TAVAKILIAN (2005) descreveram 18 espécies novas procedentes da Guiana Francesa.

Com base em material adicional estudado, objetivase descrever mais seis espécies e apresentar chave para identificação daquelas ocorrentes na América do Sul, exceto as descritas por NéOUZE \& TAVAKILIAN (2005).

Grande parte dos espécimens examinados foi enviado por James Wappes, do American Coleoptera Museum, Bulverde, Texas (ACMB), que reuniu material da Florida State Collection of Arthopods, Gainesville, Flórida (FSCA), National Museum of Natural History, Washington, D.C. (USNM) e da Coleção de Roy F. Morris, Lakeland, Flórida (CRML); também advertiu-nos de que holótipos descritos da Bolívia devem ser depositados no Museu Noel Kempf Mercado, Santa Cruz, Bolívia (MNKM). Parte do material foi retido para o Museu de Zoologia da Universidade de São Paulo (MZSP) e para o Museu da Ciências Naturais, Fundação Zoobotânica do Rio Grande do Sul, Porto Alegre (MCNZ).

\section{Xenofrea Bates, 1885}

Xenofrea Bates, 1885:373; MonnÉ, 1994:20 (cat.); Galileo \& Martins, 1999:95 (em chave).

Espécie-tipo: Xenofrea areolata Bates, 1885, designação subseqüente de MARINONI (1977).
Chave para algumas espécies sul-americanas (exceto $X$. trigonalis Bates, 1885 e as descritas por Néouze \& TAVAKILIAN, 2005).

1. Grande parte da superfície pronotal revestida por pubescência branca, compacta; terço apical dos élitros revestidos por pubescência predominantemente branca ........................... 2

Pronoto revestido por pilosidade de outras colorações; terço apical dos élitros sem pubescência branca ...................................... 3

2(1). Região dos élitros entre a base e a mancha apical com faixas longitudinais, estreitas alternadas de tegumento acastanhado e de pubescência amarelo-alaranjada; a pubescência branca do terço apical de cada élitro com limite anterior em forma de "V" invertido. Guiana Francesa, Brasil (Espírito Santo)

X. lineatipennis Zajciw, 1961

Região dos élitros entre a base e a mancha apical sem faixas longitudinais; pubescência branca do terço apical de cada élitro com o limite anterior reto e oblíquo em sentido descendente da sutura para a margem. Brasil (Minas Gerais, Santa Catarina), Paraguai (Caaguazú)

X. apicalis Melzer, 1931

3(1). Superfície dos élitros sem pubescência, exceto pequenas manchas ou faixa estreita mediana

Superfície dos élitros pubescente ................... 5

4(3). Superfície dos élitros brilhante, com grumos esparsos de pubescência amareloesbranquiçada; flagelômeros pretos. Brasil (Amazonas)

X. fulgida Galileo \& Martins, 2001 
Élitros com faixa central, estreita, de pubescência branca, oblíqua em sentido descendente da margem para a sutura; flagelômeros avermelhados com ápice escurecido. Fig. 3. Brasil (Rondônia), Bolívia (Santa Cruz) ......... $X$. camixaima sp. nov.

5(3). Sexto basal dos élitros com uma ou duas faixas transversais, pretas e estreitas

Sexto basal dos élitros sem faixas pretas ............ 7

6(5). Base de cada élitro com duas faixas transversais pretas; pronoto com duas manchas escuras, transversais e centrais; mesosterno e processo intercoxal com pubescência amarelada, uniforme. Fig. 2. Bolívia (Santa Cruz)....

X. clarkei sp. nov.

Base de cada élitro com uma faixa transversal preta; pronoto sem manchas escuras; mesosterno com faixa transversal de pubescência branca. Fig. 1. Brasil (Rondônia), Bolívia (Santa Cruz)

X. fasciolata sp. nov.

7(5). Cada élitro com uma área desenvolvida de pubescência branca, compacta e central, que atinge a margem e a sutura ou situa-se muito próximo da sutura

Outro padrão de colorido elitral ........................... 10

8(7). Pronoto e regiões circum-escutelares dos élitros com manchas de pubescência alaranjada; lados dos esternos torácicos com pubescência sedosa, amarelada, entremeada por setas escamiformes esbranquiçadas. Colômbia (Amazonas), Brasil (Rondônia) ...... ....... X. triangularis Martins \& Galileo, 2005

Pronoto e base dos élitros sem manchas de pubescência alaranjada; lados dos esternos torácicos com pubescência branca e nãoentremeada por setas escamiformes ........... 9

9(8). Disco pronotal com faixa central, estreita, longitudinal de pubescência esbranquiçada; faixa de pubescência branca no meio dos élitros larga e prolongada posteriormente pela sutura; lados do metasterno com grande mancha de pubescência branca. Brasil (Pará, Santa Catarina)

...... X. albofasciata Galileo \& Martins, 2001

Disco pronotal sem faixa centro-longitudinal; faixa de pubescência branca no meio dos élitros triangular, mais estreita e não prolongada posteriormente pela sutura; lados do metasterno sem mancha de pubescência branca densa [lado externo da clava dos metafêmures dos machos (Fig. 7) com orifício profundo]. Fig. 4. Bolívia (Santa Cruz), Argentina (Entre Ríos)

X. obscura sp. nov.

10(7). Quarto apical de cada élitro com manchas pequenas, elípticas, castanhas circundadas por pubescência amarelada. Colômbia (Amazonas)

X. exotica Galileo \& Martins, 1999

Quarto apical dos élitros sem manchas castanhas
11(10). Dorso da metade anterior dos élitros com pontos grandes, profundos e muito próximos, alguns anastomosados; áreas escuras dos élitros e dos fêmures providas de pequenos pêlos escamiformes, brancos. Fig. 5. Bolívia (Santa Cruz) ............................ punctata sp. nov.

Metade anterior dos élitros com pontos menores e não anastomosados ou pontuação praticamente ausente; fêmures e áreas escuras dos élitros sem pêlos brancos ................ 12

12(11). Dimensões maiores (comprimento 9,8 - 12,7 mm); terço anterior dos élitros atravessado por faixa transversal larga irregular, revestida por pubescência branca esparsa, da margem até a sutura. Panamá, Guiana Francesa, Brasil (Pará), Bolívia (Santa Cruz)

X. zonata Bates, 1885

Dimensões menores (comprimento 4,5-5,7 mm); terço anterior dos élitros sem faixa semelhante; pubescência branca restrita à declividade lateral dos élitros e próxima da margem. Fig. 6. Bolívia (Santa Cruz) $X$. nana sp. nov.

\section{Xenofrea apicalis Melzer, 1931}

Xenofrea apicalis Melzer, 1931:3, fig. 4; Monné, 1994:20 (cat.).

Esta espécie foi descrita com base em dois síntipos: um procedente de Minas Gerais, Mar de Espanha (MZSP) e outro sem procedência, pertencente ao "Naturhistorisches Museum", Hamburgo. Examinamos o síntipo de Mar de Espanha e acrescentamos uma nova ocorrência.

Material examinado. PARAGUAI, Caaguazú: Repatriación (4 ${ }^{\text {a }}$ Kangará), ??, 23.XI.2000, C. Aguilar col (MCNZ). BRASIL, Santa Catarina: Seara (Nova Teutônia), ㅇ? X.1977, F. Plaumann col. (MZSP).

\section{Xenofrea triangularis Martins \& Galileo, 2005}

Xenofrea triangularis Martins \& Galileo, 2005:12.

Descrita com base num macho da Colômbia, Amazonas. É registrada agora para o Brasil.

Material examinado. BRASIL, Rondônia: Ariquemes (62 km SW, Fazenda Rancho Grande), O', XI.1997, J. E. Egert col. (CRML)

\section{Xenofrea fasciolata sp. nov.} (Fig. 1)

Etimologia. Latim, fasciola $=$ diminutivo de faixa.

Fronte revestida por pubescência branca. Vértice e occipício cobertos por pubescência alaranjada. Lobos oculares superiores com seis fileiras de omatídios, tão próximos entre si quanto a metade da largura de um lobo. Antenas atingem a ponta dos élitros no ápice do antenômero IX. Escapo com pilosidade predominantemente alaranjada. Flagelômeros enegrecidos em anel apical. Pronoto com pubescência predominante alaranjada com uma mancha pouco perceptível de pubescência branca nos lados do terço basal. Lados do protórax com gibosidade acentuada 
atrás do meio e pequena elevação junto à borda anterior. Élitros com pubescência predominantemente alaranjada; cada élitro com as seguintes faixas e manchas pretas (Fig. 1): uma faixa curva, transversal, no sexto anterior que não alcança a margem e aproxima-se da sutura; uma faixa com ramo curto, oblíquo, dorsal que se funde com a sutura à frente do meio e projeta-se obliquamente para trás em direção aos ápices sem atingi-los; uma faixa estreita, lateral, próxima do meio, seguida por mancha triangular, fundida com a margem; pubescência branca atrás da faixa preta basal, entre a faixa lateral e na reentrância das faixas oblíquas e na declividade apical, onde é abundantemente entremeada de pubescência alaranjada. Extremidades elitrais arredondadas em conjunto, precedidas por elevação transversal. Face ventral com pubescência alaranjada, exceto no prosterno e no mesosterno. Pedúnculo dos fêmures com tegumento avermelhado; clava com tegumento preto.

Dimensões, em mm. Comprimento total, 7,0; comprimento do protórax, 1,5; maior largura do protórax, 2,2; comprimento do élitro, 5,1; largura umeral, 2,8 .

Material-tipo. Holótipo ơ, BRASIL, Rondônia: Ariquemes (62 km SW, Fazenda Rancho Grande), XI.1994, C. W. \& L. B. O'Brien col., luz ultravioleta e de mercúrio (MZSP). Parátipo + , BOLÍVIA, Santa Cruz: Buena Vista $(3,7 \mathrm{~km}$ SSE, Hotel Flora \& Fauna, 430 m), 5-15.XI.2001, D. K. Dozier col. "tropical transition forest, blacklight trap" (FSCA)

\section{Xenofrea clarkei sp. nov.}

(Fig. 2)

Etimologia. O epíteto é uma homenagem a Robin Clarke, coletor do holótipo.

Fronte revestida por pubescência branca. Vértice com pubescência amarelada entremeada por pêlos escamiformes $(32 \mathrm{x})$ amarelados. Lobos oculares superiores com seis fileiras de omatídios; distância interocular superior menor que a largura de um lobo. Escapo com pêlos escamiformes amarelados. Flagelômeros com anel apical preto. Lados do protórax com tubérculo subacuminado situado atrás do meio; tubérculo junto à margem anterior ausente. Pronoto recoberto por pubescência amarelada, mais concentrada em duas faixas laterais que se estendem da base ao ápice dos tubérculos laterais do protórax; no meio, duas manchas transversais pretas. Élitros (Fig. 2) com pubescência predominantemente amarelada; com três faixas pretas, paralelas, estreitas, transversais, uma na declividade basal, outra próxima, no sexto anterior e outra mais afastada, no terço anterior; manchas longitudinais pretas no meio, faixa preta oblíqua no sentido da sutura para a margem no terço dorso-apical; pubescência branca entre as faixas pretas anteriores e numa faixa longitudinal na declividade apical. Face ventral com pubescência escamiforme esbranquiçada nos mesepisternos, mesepimeros e lados do metasterno. Pedúnculo dos fêmures e base das metatíbias com tegumento avermelhado; clavas e metade apical das metatíbias com tegumento preto.

Dimensões em $\mathrm{mm}, \sigma^{3} / 9$ respectivamente. Comprimento total, 6,0-6,6/5,8; comprimento do protórax, 1,3-1,4/1,1; maior largura do protórax, 1,8-2,0/1,6; comprimento do élitro, 4,5-4,9/4,4; largura umeral, 2,2$2,5 / 2,1$.

Material-tipo. Holótipo ơ', BOLÍVIA, Santa Cruz: Buena Vista (Hotel Flora \& Fauna, 4-6 km SSE), 15-28.II.2003, R. Clarke col. (MNKM). Parátipos: mesmos dados do holótipo, 4 o (2 ACMB, MZSP, MCNZ,); 우 (ACMB).

\section{Xenofrea camixaima sp. nov.}

(Fig. 3)

Etimologia. Tupi, camixaima $=$ nu, alusivo aos élitros quase sem pubescência.

Tegumento castanho-avermelhado com escasso revestimento de escamas. Cabeça com pubescência esparsa, branca na fronte e amarelada no vértice. Lobos oculares superiores com cinco fileiras de omatídios separados entre si por distância igual ao dobro da largura de um lobo. Escapo com pubescência amarelada, esparsa. Flagelômeros com tegumento avermelhado e anel apical preto. Lados do protórax com gibosidade no nível do terço posterior. Pronoto com escassa pubescência amarelada, localizada principalmente nos lados da metade posterior. Élitros (Fig. 3) com aspecto brilhante, cada um com uma faixa de pubescência branco-amarelada, oblíqua, descendente da margem para a sutura; pequeno pincel de escamas brancoamareladas, situado dorsalmente no nível do quarto anterior; terço apical com escamas branco-amareladas de concentração variável. Face ventral com pubescência esparsa, esbranquiçada. Pedúnculo dos fêmures e base das metatíbias com tegumento avermelhado; clavas e metade apical das metatíbias com tegumento preto.

Dimensões em $\mathrm{mm}$, respectivamente $0^{2} / 9$. Comprimento total, 6,1-6,4/6,0; comprimento do protórax, 1,2-1,3/1,3; maior largura do protórax, 1,9-2,0/1,9; comprimento do élitro, 4,4-4,8/4,3; largura umeral, 2,6$2,7 / 2,7$.

Material-tipo. Holótipo O’, BOLÍVIA, Santa Cruz: Buena Vista (Hotel Flora \& Fauna, 3,7 km SSE, $405 \mathrm{~m}, 17^{\circ} 29,949^{\prime} \mathrm{S}$, $63^{\circ} 33,152^{\prime}$ W), 5-15.XI.2001, M. C. Thomas \& B. K. Dozier col., "tropical transition forest" (USNM). Parátipos: mesmos dados do holótipo, o", "black light trap" (MZSP); + , mesmos dados do holótipo, 15-22.XI.2001, M. C. Thomas \& B. K. Dozier col., "black light trap, tropical transition forest" (FSCA); + , 5-15.XI.2002, M. C. Thomas \& B. K. Dozier col., "tropical transition forest" (FSCA); (Hotel Flora \& Fauna, 4-6 km SSE), O', 2-9.I.2004, R. Clarke col. (ACMB); ㅇ, 22-30.XI.2003, R. Clarke col. (MCNZ). BRASIL, Rondônia: Ariquemes (62 km SW, Fazenda Rancho Grande), 2 , XI.1994, C. W. \& L. B. O'Brien col., luz ultravioleta e de mercúrio (ACMB, MCNZ).

\section{Xenofrea obscura sp. nov.} (Figs. 4, 7)

Etimologia. Latim, obscurus $=$ obscura; relativo ao padrão de cor.

Fronte revestida por pubescência branca esparsa. Vértice e escapo com pubescência esbranquiçada escassa. Lobos oculares superiores com seis fileiras de omatídios, tão afastados entre si quanto o diâmetro de um lobo. Antenas avermelhadas; flagelômeros III e IV com o ápice enegrecido ou não. Lados do protórax com gibosidade central e tubérculo mais curto ou inexistente 
junto à orla anterior. Pronoto com pubescência esparsa, amarelada. Tegumento elitral avermelhado e recoberto por pubescência branca, exceto: tegumento preto e escassamente pubescente no terço basal, numa área oblíqua, mediana e em mancha sutural no terço posterior, às vezes, unida à faixa central. A pubescência branca da metade anterior dos élitros (Fig. 4) reveste uma área triangular da margem até a sutura. Face ventral recoberta por pubescência esbranquiçada. Fêmures com tegumento inteiramente preto ou avermelhado na base. Nos machos
(Fig. 7), a face externa dos metafêmures apresenta uma depressão grande, suboval, que ocupa quase toda a clava, com muitos pêlos internos. Nas fêmeas, metafêmures normais. Metatíbias pretas.

Variabilidade. Um dos parátipos () apresenta a metade apical dos élitros com redução do colorido preto.

Dimensões em $\mathrm{mm}$, o/ $/$ respectivamente. Comprimento total, 5,5/5,7; comprimento do protórax, 1,0/ 1,1; maior largura do protórax, 1,6/1,7; comprimento do élitro, 4,1/4,3; largura umeral, 2,1/2,3.
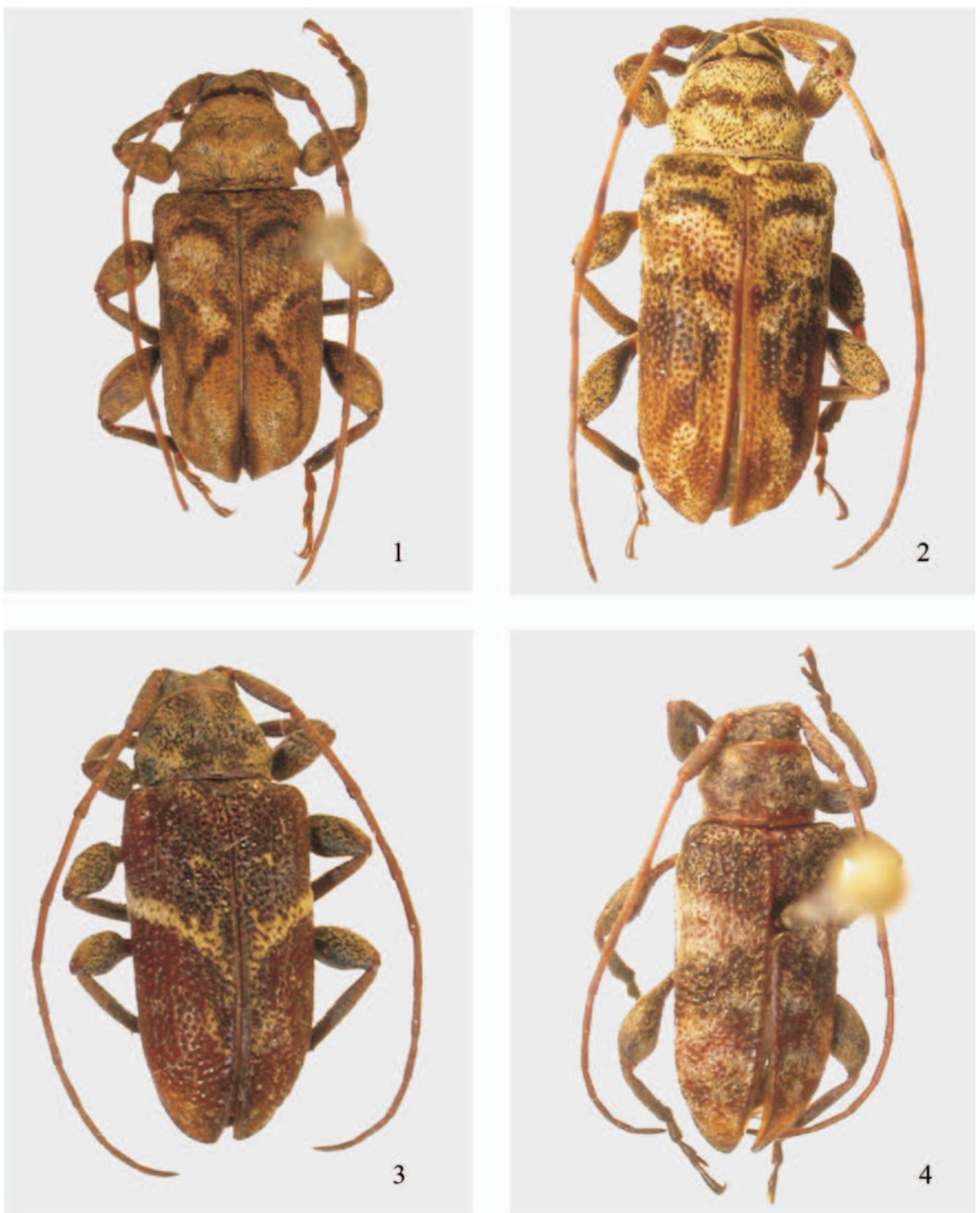

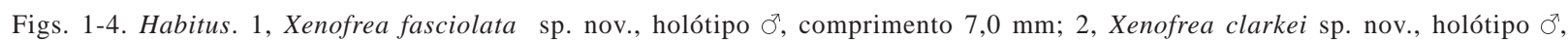
comprimento 6,6 mm; 3, Xenofrea camixaima sp. nov., holótipo o', comprimento 6,4 mm; 4, Xenofrea obscura sp. nov., holótipo ㅇ, comprimento $5,5 \mathrm{~mm}$; 
Material-tipo. Holótipo + , ARGENTINA, Entre Ríos: Liebig, XI.1988, sem nome do coletor (MCNZ). Parátipos: 2 , BOLIVIA, Santa Cruz: Buena Vista (Hotel Flora \& Fauna, 3,7 km SSE, $\left.405 \mathrm{~m}, 17^{\circ} 29,949^{\prime} \mathrm{S}, 63^{\circ} 33,152^{\prime} \mathrm{W}\right), 5-15 . X I .2001$, M. C. Thomas \& B. K. Dozier col., "tropical transition forest" (FSCA, MZSP); (Hotel Flora \& Fauna, 4-6 km SSE), O, 2124.XI.2003, Wappes, Morris \& Nearns col. (ACMB); ("vicinity" Hotel Flora \& Fauna),, , 27-31.X.2002, Morris \& Wappes col. (CRML).

\section{Xenofrea punctata sp. nov.}

(Fig. 5)

Etimologia. Latim, punctata $=$ pontuada; relativo aos pontos profundos no dorso dos élitros.

Fronte revestida por pubescência branca. Vértice com pubescência amarelada. Lobos oculares superiores com pelo menos dez fileiras de omatídios, tão distantes entre si quanto a largura de um lobo nos machos e 1,3 vezes nas fêmeas. Antenas com tegumento avermelhado, atingem as extremidades elitrais na ponta do antenômero VIII nos machos e no ápice do antenômero IX nas fêmeas. Escapo com escassas escamas amareladas entremeadas por escamas brancas. Lados do protórax com pequena elevação junto à borda anterior e com gibosidade acentuada atrás do meio. Tegumento do pronoto acastanhado com áreas de pubescência escamiforme amarelada: faixa estreita centro-longitudinal e quatro manchas, duas a cada lado; restante da superfície pronotal com escamas esparsas brancas e acastanhadas. Pontuação do pronoto moderada e profunda. Élitros castanho-avermelhados com áreas de pubescência alaranjada (Fig. 5) em cada um: mancha basal próxima do escutelo; faixa descontínua no terço basal, oblíqua em sentido descendente da margem para a sutura; faixa curta, oblíqua pouco à frente do meio, próxima da sutura; pequena mancha lateral, perto do meio; conjunto de três manchas logo atrás do meio; faixa longitudinal, irregular, no dorso do quarto apical. Superfície dos élitros, entre as manchas alaranjadas, revestida por pubescência acastanhada entremeada por escamas brancas esparsas; no terço anterior, área oblíqua sutural, coberta por escamas brancas esparsas. Metade anterior dos élitros próximo da sutura com pontos grossos. Fêmures castanhos com as bases avermelhadas, cobertos por pubescência esbranquiçada com escamas brancas entremeadas. Face ventral do corpo revestida por pubescência predominantemente branca.

Dimensões em $\mathrm{mm}, \sigma^{T} / 9$ respectivamente. Comprimento total, 7,0/9,1-9,7; comprimento do protórax, 1,6/2,0-2,1; maior largura do protórax, 2,2/2,9-3,0; comprimento do élitro, 5,1/6,9-7,1; largura umeral, 2,8/3,53,9 .

Material-tipo. Holótipo O’’, BOLÍVIA, Santa Cruz: Buena Vista (Hotel Flora \& Fauna, 4-6 km SSE), 3-8.X.2004, Wappes \& Morris col. (MNKM). Parátipos: ditto, + , 10-15.XI.2003, R. Clarke col. (MZSP); + , 13-16.XI.2003, Wappes, Morris \& Nearns col. (ACMB); , 21-24.XI.2003, Wappes, Morris \& Nearns col. $(\mathrm{ACMB})$

\section{Xenofrea nana sp. nov.}

(Fig. 6)

Etimologia. Latim, nanus = pequeno; referente às dimensões reduzidas.

Tegumento da cabeça castanho-avermelhado. Fronte coberta por pêlos brancos. Vértice com pêlos
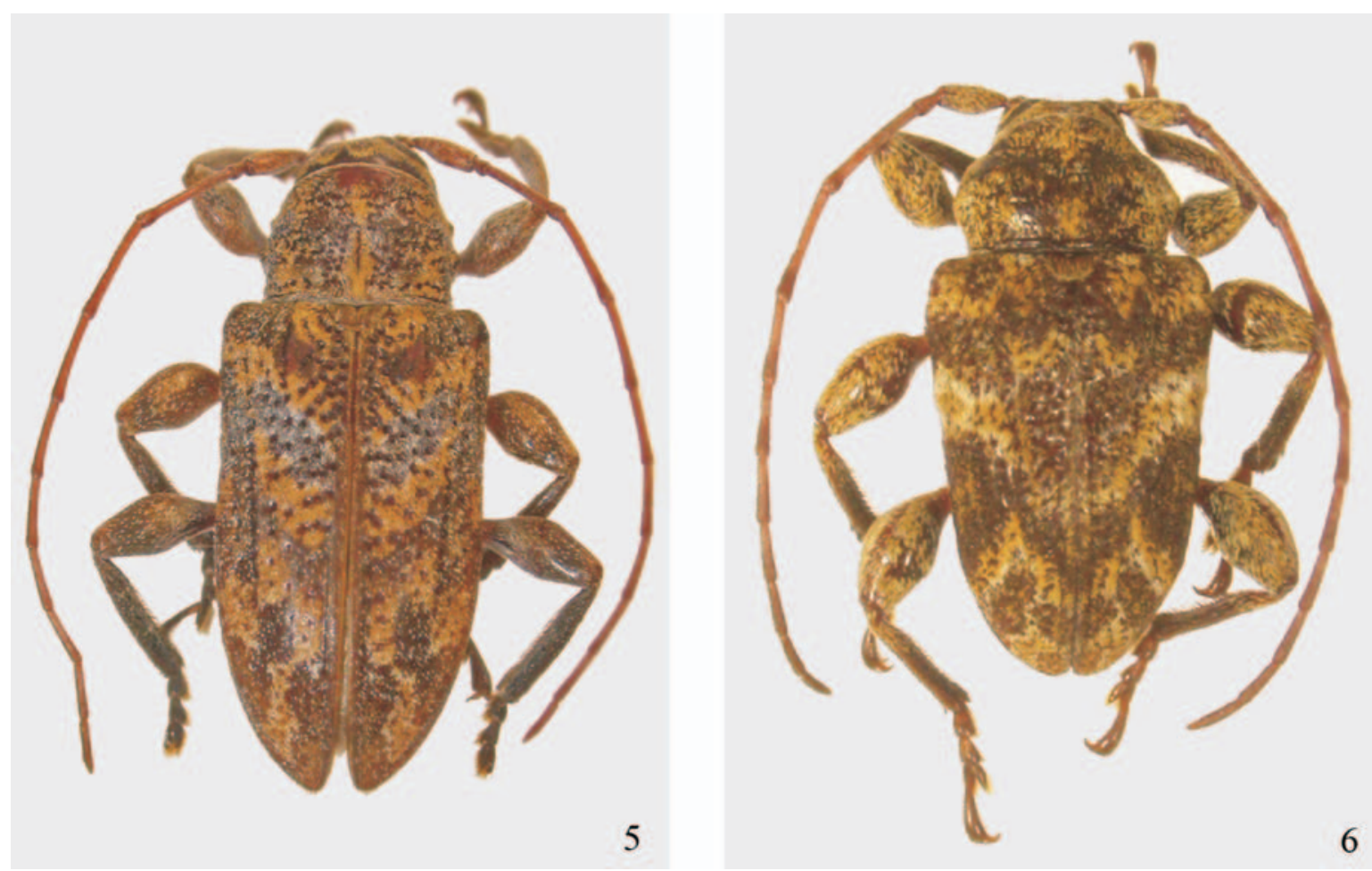

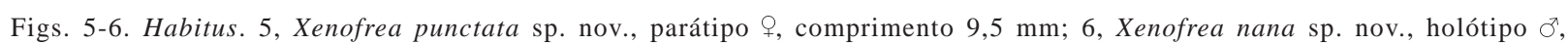
comprimento $5,7 \mathrm{~mm}$. 
amarelos e área central quase glabra. Lobos oculares superiores com sete fileiras de omatídios, tão afastados entre si quanto o dobro da largura de um lobo. Antenas com tegumento avermelhado, ultrapassam o ápice elitral a partir do antenômero VIII nos machos e atingem a ponta dos élitros nas fêmeas; escapo revestido por escamas predominantemente amarelo-alaranjadas. Protórax com tegumento acastanhado; pubescência predominante branca sobre as gibosidades laterais que, às vezes, pode faltar. Pronoto com pilosidade escamiforme, alaranjada próxima à orla anterior, nos lados e em pequena mancha no centro da base. Élitros castanho-avermelhados; cada um com (Fig. 6): faixa transversal, descontínua, de pubescência alaranjada junto à base; pequena área coberta de pubescência alaranjada, dorsal, no quarto

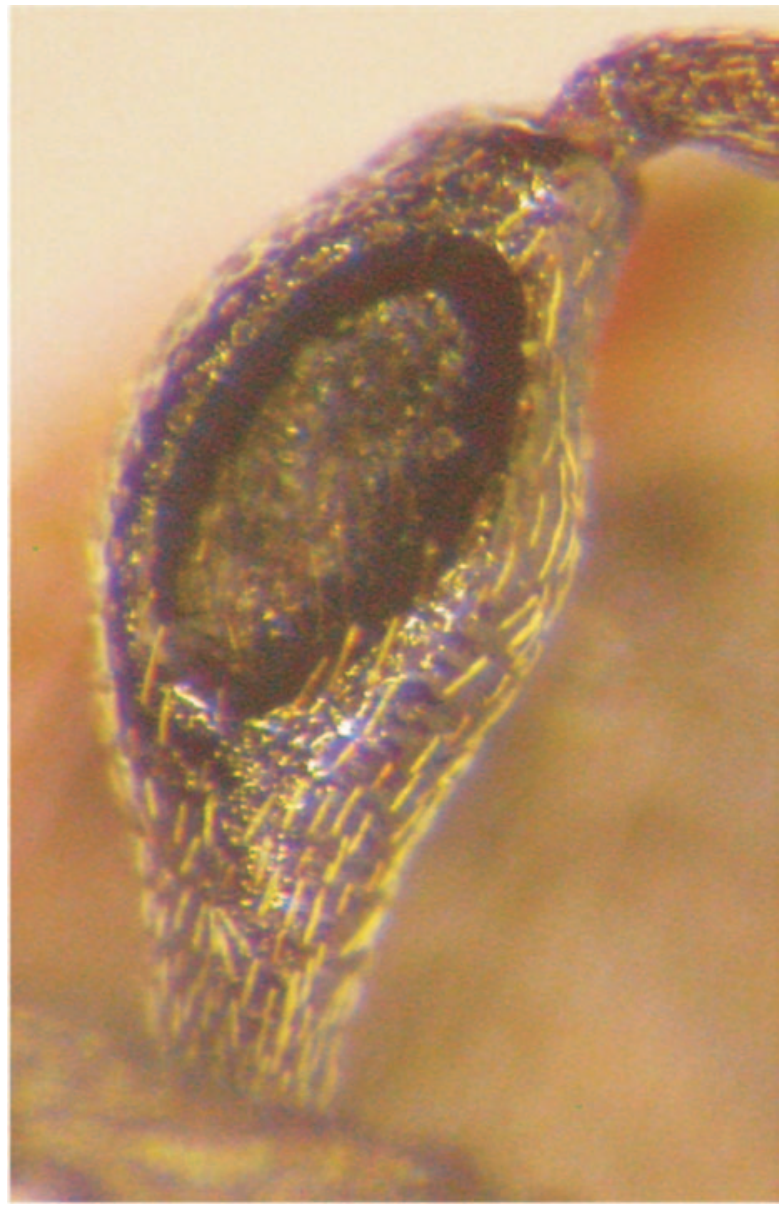

Fig.7. Metafêmur do o de Xenofrea obscura sp. nov., comprimento $1,4 \mathrm{~mm}$. anterior junto à sutura; faixa oblíqua em sentido descendente da margem para a sutura e mais larga junto à margem de pubescência branca nos lados e alaranjada perto da sutura; mancha no terço apical em forma de "V" invertido de pubescência alaranjada internamente com pubescência branca; extremidades ocupadas por manchas de pubescência alaranjada e branca. Fêmures com tegumento castanho na clava e avermelhado no pedúnculo, com escamas predominantemente alaranjadas. Lado inferior do corpo revestido por pubescência branca.

Dimensões em mm, o $1 / 9$ respectivamente. Comprimento total, 4,5-5,7/5,1; comprimento do protórax, 1,0-1,8/1,1; maior largura do protórax, 1,6-2,4/1,8; comprimento do élitro, 3,3-4,3/3,8; largura umeral, 2,0$2,8 / 2,3$

Material-tipo. Holótipo ơ', BOLÍVIA, Santa Cruz: Buena Vista (Hotel Flora \& Fauna, 4-6 km SSE), 1-16.IV.2003, R. Clarke col. (MNKM). Parátipo $0^{7}$ com os mesmos dados do holótipo (MZSP); ditto, parátipo o", 17-30.IV.2003, R. Clarke col. (ACMB); ("vicinity" Hotel Flora \& Fauna), parátipo + , 14-16.X.2000, R. Morris col. (CRML)

Agradecimentos. A James Wappes (ACMB) e Roy Morris (CRML) pelo empréstimo de material para estudo; a Rafael Santos de Araujo (MCNZ) pela execução das fotografias.

\section{REFERÊNCIAS BIBLIOGRÁFICAS}

Bates, H. W. 1885. Biologia Centrali-Americana, Insecta, Coleoptera, suppl. to Longicornia. London, British Museum (Natural History). v. 5, p.249-436, est. 17-24.

Galileo, M. H. M. \& Martins, U. R. 1999. Sobre espécies de Lamiinae (Coleoptera, Cerambycidae) da Colômbia e do Brasil com garras tarsais divaricadas. Papéis Avulsos de Zoologia 41(6): $83-104$

—. 2001. Novas espécies de Lamiinae (Coleoptera, Cerambycidae) neotropicais. Iheringia, Série Zoologia, (90):59-70.

Marinoni, R. C. 1977. Some genera of Lamiinae and their typespecies (Coleoptera, Cerambycidae). Dusenia 10(1):37-55.

Martins, U. R. \& Galileo, M. H. M. 2005. Cerambycidae (Coleoptera) da Colômbia. VII. Novos táxons, novos registros, nova sinonímia, nova combinação e novo nome. Revista Brasileira de Zoologia 22(1):5-18.

Melzer, J. 1931. Cerambycideos neotrópicos, principalmente do Brasil. Revista de Entomologia 1(1):1-15.

Monné, M. A. 1994. Catalogue of the Cerambycidae (Coleoptera) of the Western Hemisphere. Part XVII. São Paulo, Sociedade Brasileira de Entomologia. 110p.

Néouze, G. -L. \& Tavakilian, G. L. 2005. Matériaux pour une révision des Xenofreini - I. Espèces nouvelles de Guyane (Coleoptera, Cerambycidae, Lamiinae). Coléoptères 11(13): 129-164.

Zajciw, D. 1961. Dois gêneros e três espécies novas de longicórneos do Brasil (Col., Cerambycidae). Anais da Academia Brasileira de Ciências 33(2):217-224. 